\title{
Prevalence of allergic sensitization to Russian thistle in Kingston and the South-eastern Ontario catchment area; a retrospective chart review
}

\author{
Nina Lakhani ${ }^{* *}$, Anne K Ellis ${ }^{1,2}$ \\ From Canadian Society of Allergy and Clinical Immunology Annual Scientific Meeting 2010 \\ Victoria, Canada. 3-6 November 2010
}

\section{Background}

Russian thistle has only recently been identified as a potentially clinically important allergen. In the third phase of the National Health and Nutrition Examination Surveys conducted in the USA (1988 to1994) over 15\% of tested individuals had positive skin-test responses to this extract. The rate of skin test positivity to Russian thistle in Canada is unknown.

\section{Objective}

To determine the prevalence of skin test positivity to Russian Thistle in patients from Kingston and the Southeastern Ontario catchment area, and the possible clinical significance of the same.

\section{Methods}

A retrospective chart review was performed to document the rate of sensitization amongst tested patients to Russian thistle extract (Hollister-Steir). Only patients with appropriate histamine responses were included. We collected demographic data in addition to the presence/ absence of relevant clinical symptoms.

\section{Results}

Of 410 charts reviewed, 170 underwent skin testing to Russian thistle. Of these, 17(10\%) were positive. Of the test-positive cohort, $47 \%(8 / 17)$ had symptoms that correlated seasonally with the predominant Russian thistle pollen season (August-October). The mean age of skin-test positive individuals was 35.2 years. $82 \%$ and $52.9 \%$ of these had concomitant positive skin tests to ragweed and birch, respectively, allergens with known cross-reactivity.

\section{Conclusions}

This preliminary evaluation suggests that the prevalence of skin test positivity to Russian thistle in the studied area is approximately $10 \%$, with about half of these individuals reporting correlative seasonal symptoms. Including Russian thistle in routine skin testing panel may better establish the clinical significance of this environmental allergen.

This study was approved by the Queen's University Health Sciences and Affiliated Teaching Hospitals Research Ethics Board, with no financial interest or funding provided.

\section{Author details}

'Department of Medicine, Queen's University, Kingston, ON, Canada. ${ }^{2}$ Department of Microbiology \& Immunology, Queen's University, Kingston, ON, Canada.

Published: 4 November 2010

doi:10.1186/1710-1492-6-S2-P18

Cite this article as: Lakhani and Ellis: Prevalence of allergic sensitization to Russian thistle in Kingston and the South-eastern Ontario catchment area; a retrospective chart review. Allergy, Asthma \& Clinical Immunology 2010 6(Suppl 2):P18.

* Correspondence: nina.lakhani@queensu.ca

'Department of Medicine, Queen's University, Kingston, ON, Canada

Full list of author information is available at the end of the article 